\title{
Management of Large Cirsoid Aneurysms of the Scalp Using Tissue Expanders, Intravascular Occlusion, and En Bloc Excision
}

\author{
EMAN NAGY MOHAMED, M.D.; HANY SAAD SETTA, M.D. and AHMED EL-SHAHAT, M.D. \\ The Department of Plastic Surgery, Faculty of Medicine, Ain Shams University, Egypt
}

\begin{abstract}
Background: Arteriovenous malformations of the scalp consist of abnormally connecting arterial feeding vessels and draining veins that are devoid of a normal capillary bed within the subcutaneous fatty layer of the scalp. The name "cirsoid" in cirsoid aneurysm is derived from the Greek word kirsos meaning varix or varicose vein. The en bloc excision of scalp tissues affected by aneurysm is preferable to selective ligation of the feeding and draining vessels. Because the management of cirsoid aneurysm is an elective procedure, it is best to use tissue expanders to create sufficient scalp flaps to reconstruct the site of the excised lesion in the first stage. Preoperative embolization greatly reduces blood loss during resection.
\end{abstract}

Aim of the Work: To present the successful management of cirsoid aneurysms of the scalp using tissue expanders, endovascular occlusion, and en bloc excision.

Material and Methods: Five patients who had presented cirsoid aneurysms of the scalp (two temporoparietal, two frontal, and one occipital) were managed successfully using three stages of intervention. The first stage was the application of one or two tissue expanders, in which expanders were applied under the normal (non-affected) scalp in the subgaleal plane; expansion was then performed weekly for 3-4 months. The second stage involved endovascular occlusion through endovascular neuroradiology. The third stage was performed the day after occlusion and included en bloc excision, the delivery of tissue expanders, and reconstruction of the site of excision using scalp flaps. The postoperative period was uneventful. Six months to three years of following-up showed no recurrence.

Conclusion: We conclude that the three-stage management of large cirsoid aneurysms of the scalp (application of tissue expanders, endovascular occlusion, then en bloc excision and reconstruction) provides excellent results.

Key Words: Cirsoid aneurysm - Vascular malocclusion Tissue expansion - Endovascular occlusion Scalp.

\section{INTRODUCTION}

Cirsoid aneurysms are rare arteriovenous fistulas of the scalp whose etiology is usually congenital, although traumatic fistulas have also been reported [1-3]. The condition is called "cirsoid" (from the Greek kirsos, meaning "varix," or varicose vein) because of the characteristic variceal dilatation of the draining veins. The various names that are used to describe vascular malformations of the scalp include aneurysm cirsoide, aneurysma serpentinum, aneurysm racemosum, plexiform angioma, arteriovenous fistula and arteriovenous malformation $(\mathrm{AVM})[\mathbf{1 , 2 , 4 ]}$.

Cirsoid aneurysms of the scalp were first described in 1833 by Brecht [5]. Only 10\%-20\% of these arteriovenous fistulas develop following penetrating trauma to the scalp. Traumatic arteriovenous malformation of the scalp develops months or even years after the scalp trauma. While congenital arteriovenous malformation of the scalp (the remaining 80\%-90\%) might be present at birth, for most patients it is asymptomatic until adulthood [6-8].

In $90 \%$ of patients, the superficial temporal artery is the main supply to the fistula, with only one dominant feeding artery in $71 \%$ of those patients [9]. In the remaining $29 \%$ of cases usually involve both the superficial temporal and occipital arteries [5,9].

The most important distinction regarding AVM is between single-hole arteriovenous fistula (usually traumatic) and more complex lesions, which are thought to be (congenital). These more complex lesions are characterized by a network of abnormal channels (nidi) between the arterial feeder (s) and the draining vein or veins (i.e., an AVM). They also may have components with no intervening nidi (i.e., fistulas) [10].

The management of scalp AVM is difficult because of the scalp's high shunt flow, intracranial communication, complex vascular anatomy, and cosmetic problems. The indication of treatment includes cosmetic relief of the pulsatile or nonpulsatile mass and the prevention of hemorrhage and other symptoms such as headache and tinnitus [5,11-14]. 
It is well known in the literature that the only effective method of preventing the evolution of $\mathrm{AVM}$ of the scalp is to exclude the lesion completely from circulation [15]. The management of AVMs of the head and neck includes observation, ligation of the feeding arteries, embolization, and surgical resection $[\mathbf{2 , 7 , 9 , 1 6 , 1 7 ]}$, or a combination of these elements $[\mathbf{1 8 , 1 9 ]}$. Ligation of the feeding arteries was one of the earliest treatment methods for this condition, although recurrence nearly always ensues because of the development of collateral vessels $[\mathbf{1 , 2 , 1 7 ]}$. The collateral vessels that develop following ligation of the feeding arteries might parasitize blood flow from the brain, which can lead to ischemic complications [20].

Endovascular treatment may be applied in order to decrease the hemorrhage and to facilitate surgical treatment or the direct treatment of AVMs [4,9,21,22]. The pre-operative embolization of both feeders and nidus before surgery is safer than embolization of the feeders alone for reducing the risk of excessive hemorrhage [4]. Three different approaches have been described in the literature for accessing the fistula; femoral transarterial catheterization, femoral transvenous catheterization and direct percutaneous catheterization of the feeding arteries or draining veins $[\mathbf{1 3 , 1 8 , 2 3 - 2 6 ]}$.

Surgical excision is the most common and successful method of dealing with vascular scalp lesion $[\mathbf{6 , 2 4 , 2 7 , 2 8 ]}$. Surgical treatment is particularly indicated for preventing bleeding, the resolution of cosmetic problems, and for the treatment of the accompanying issues of tinnitus and headache $[\mathbf{4 , 2 1 , 2 9 ]}$. Various techniques have been used to control hemorrhage during surgery, including percutaneous sutures of the feeding vessels [6], Inter- locking sutures along the line of incision, and the use of a scalp tourniquet and an intestinal clamp over the base of the flap [30]. A step-wise incision with careful pressure control is useful for controlling scalp bleeding [11].

The excision of large arteriovenous malformation of the scalp leaves a large defect that requires reconstruction; the Ideal reconstruction is the use of hair-bearing skin flaps. Marotta et al., [31] expanded the scalp adjacent to the arteriovenous malformation to prepare a hair-bearing skin flap that they used for reconstruction.

The lack of descriptions of this technique in the literature, together with its absence in plastic surgery journals, encouraged us to revisit this technique. The aim of this work is thus to present a complete excision using a combined approach of preoperative endovascular occlusion followed by radical excision and coverage of the defect via expanded adjacent scalp.

\section{PATIENTS AND METHODS}

This is a retrospective case series study on five patients with cirsoid aneurysms who were treated from March 2012 to December 2015. Diagnosis was based on both a clinical picture of pulsatile swelling in the scalp with bruit and thrill and on the intravascular dye injection (angiography). None of our patients presented with hemorrhage, and none had neurological deficits. The patients' lesions were located in the temperoparietal region in two patients, in the frontal region in two patients and in the occipital region in one patient. No intracranial lesion was demonstrated in any patient. Table (1) shows the data of the five patients included in this study.

Table (1): Data of the 5 patients included in this study.

\begin{tabular}{|c|c|c|c|c|c|}
\hline & Patient 1 & Patient 2 & Patient 3 & Patient 4 & Patient 5 \\
\hline Age & 22 years & 26 years & 29 years & 30 years & 19 years \\
\hline Sex & Male & Male & Male & Male & Male \\
\hline History of trauma & None & None & None & None & None \\
\hline Site & Temporoparietal & Temporoarietal & Frontal & Frontal & Occipital \\
\hline Size & $12 \mathrm{~cm}$ diameter & $15 \mathrm{~cm}$ diameter & $9 \mathrm{~cm}$ diameter & $8 \mathrm{~cm}$ diameter & $10 \mathrm{~cm}$ diameter \\
\hline Expanders & One rectangular & Two rectangular & Two rectangular & Two rectangular & One rectangular \\
\hline Duration of expansion & 3 months & 3.5 months & 3.5 months & 2.5 months & 4 months \\
\hline Follow up period & 3 years & 2 years & One years & 9 months & 6 months \\
\hline Recurrence & None & None & None & None & None \\
\hline
\end{tabular}

In an attempt to completely eradicate the AVM, one or two large, rectangular tissue expanders were then placed in the less-affected scalp area in the subgaleal plane at least $3 \mathrm{~cm}$ from the edge of the
AVM. All incisions for the expander placement were perpendicular to the expansion axis and were distant from the AVM. Ports were buried in all patients; the use of suction drains for a few days 
was the routine for all cases. In the second stage and before excision, aggressive preoperative coiling (occlusion) of the malformation was performed by the intervention neuroradiology department in our hospital. One day after endovascular occlusion, complete excision of the malformation was then performed. Interlocking sutures along the line of incision were used in all patients prior to surgical excision to decrease blood loss. The expanded scalp was then transposed for coverage of the entire defect.

\section{RESULTS}

All patients were treated according to the proposed protocol. Expansion was successful in all patients despite the seropurulent collection that was detected in one patient around the expanders; this was managed successfully by exteriorization of the ports. The operating time during the appli-

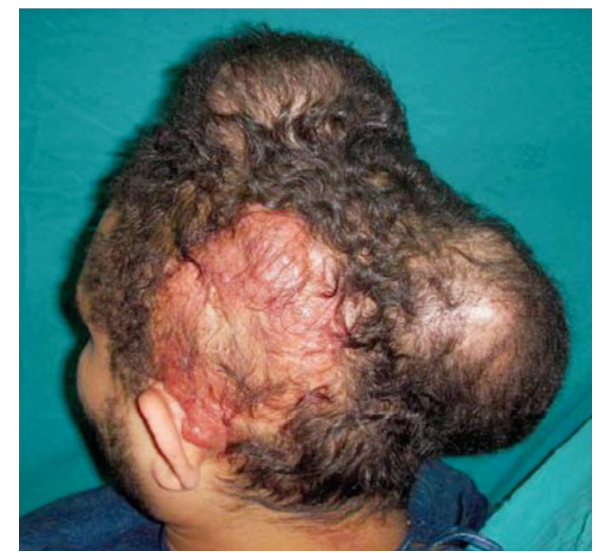

Fig. (1): A photo shows large cirsoid aneurysm in scalp (left temporoparietal region) of 26 year old male patient with two inflated tissue expanders underneath the adjacent sound scalp.

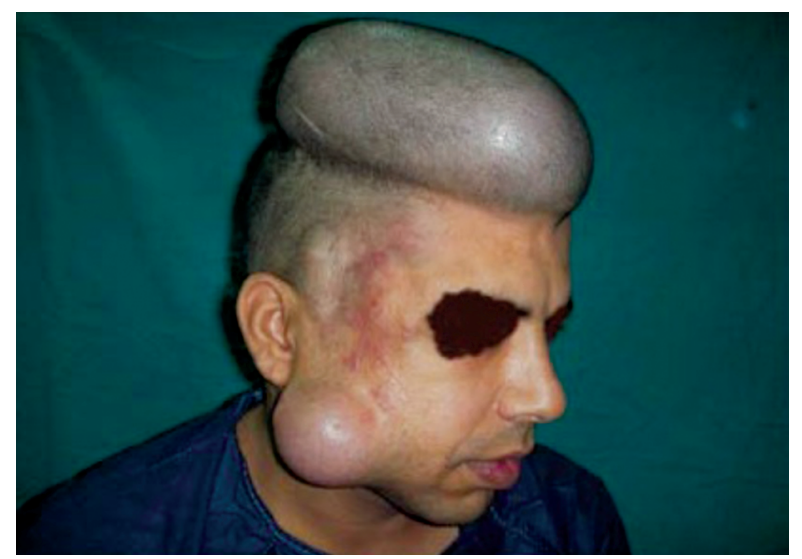

Fig. (3): A photo shows cirsoid aneurysm in the right frontal region of a 30 year old male patient with two inflated tissue expanders in the adjacent scalp and cheek cation of the tissue expanders ranged from 30 to 45 minutes in the five cases, while en bloc excision and reconstruction ranged from 90 to 120 minutes. Blood loss ranged from 350 to $1000 \mathrm{ml}$ in the en bloc excision. Blood transfusion of $500 \mathrm{ml}$ whole blood was the routine in all five cases.

All the preoperative symptoms and signs were eliminated. The expanded flaps survived completely, and all the patients had excellent postoperative cosmetic appearance; No postoperative complications related to the surgery had occurred. The patients were followed-up with for a period ranged from 6 to 36 months; no recurrences occurred during the follow-up period. Figs. (1-6) show three patients after application of the tissue expanders and before excision of the lesions $(1,3,5)$ and after excision of the cirsoid aneurysms and advancement of the expanded flaps $(2,4,6)$.

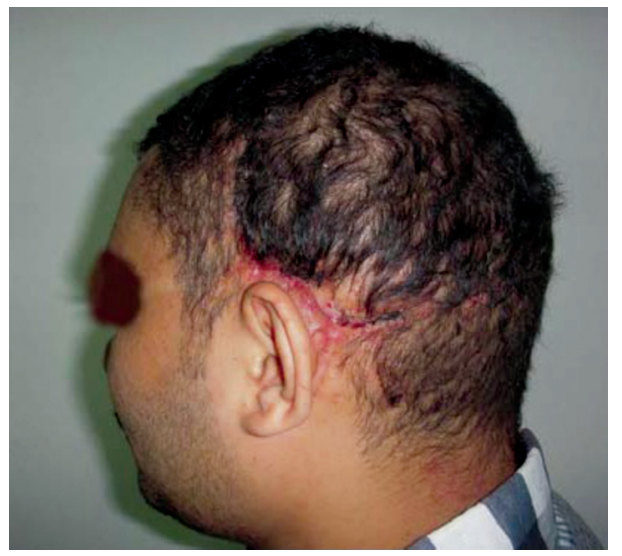

Fig. (2): A photo of the same patient in Fig. (1) after en block excision of the cirsoid aneurysm and advancement of expanded scalp flaps

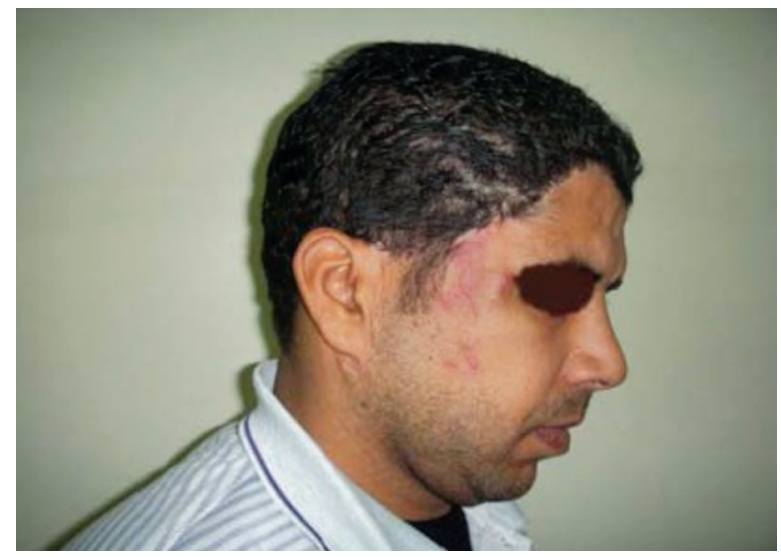

Fig. (4): A photo shows the same patient in Fig. (3) after en block excision of the cirsoid aneurysm and advancement of expanded flaps to reconstruct the right frontal region and anterior hair line. 


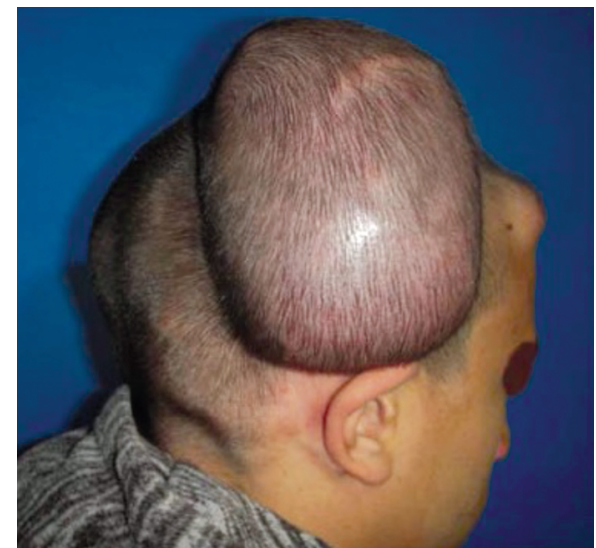

Fig. (5): A photo shows cirsoid aneurysm in the right occipital and postauricular regions in a 19 year old male patient with inflated tissue expander underneath the adjacent sound scalp.

\section{DISCUSSION}

Cirsoid aneurysms are rare despite the intense vascularity of the scalp and the relatively high frequency of trauma to this region [3]. Most of the reports in the literature consist of individual case reports; very few studies consist of sufficient number of patients $[\mathbf{7 , 1 3 , 1 8 ]}$. One study from the literature mentioned that these lesions usually begin as a small, subcutaneous lump on the head that over a period of time evolves into a grotesque, deforming mass [13 ]. A bruit or a throbbing headache might be the chief complaint in some patients; other presenting symptoms include pulsatile tinnitus or (rarely) hemorrhage from the mass [25]. Large lesions may occasionally be associated with scalp necrosis. Congestive heart failure has occurred with large fistulas [18]. The same sequelae were found in our patients, except for the absence of hemorrhage or congestive heart failure.

Definitive treatment for the condition requires controlled en bloc excision, in which the entire malformation is excised [15,32]. In the five patients included in this study coiling (occlusion) of the arteriovenous malformations was done before the en bloc excision to limit intraoperative bleeding; interlocking sutures were also used for the same purpose. Blood loss still took place despite these precautions, so blood transfusion was the routine.

Many techniques have been used to cover scalp defects; some of these include direct closure in small AVM defects, skin and galeal-pericranial flaps, compound musculocutaneous flaps, as well as free-tissue transfer $[\mathbf{3 4 , 3 5}]$. These techniques were not applicable in the five patients included in this study, however, because the lesions were

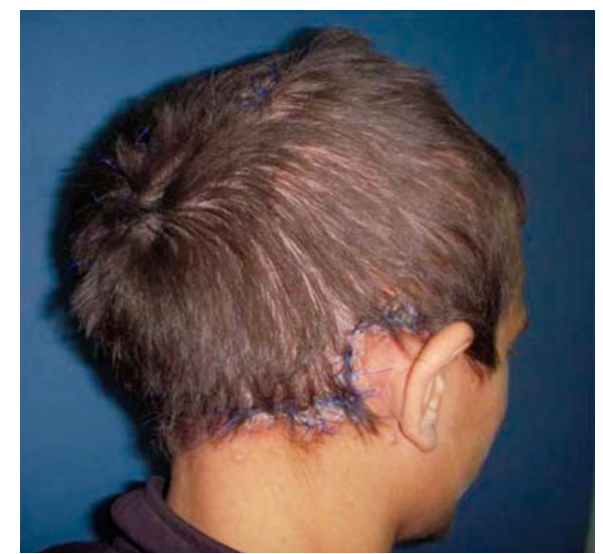

Fig. (6): A photo the same patient in Fig. (5) after en block excision of the cirsoid aneurysm and advancement of the expanded scalp flap.

large and the defects that were left after en bloc excision were even larger. Although Free-tissue transfer can cover large defects, it requires normal vessels for anastomosis and the skin provided is non hair bearing. Donor-site morbidity is another disadvantage of the use of free flaps.

Similarly to the technique Marotta et al., [31] used, planned tissue expansion of the adjacent scalp allowed for large hair-bearing flaps to cover the resultant defects after en bloc excision.

Periexpander seropurulent collection in one patient was managed by exteriorization of the buried ports for drainage in order to salvage the infected expanders (as mentioned by Elshahat [36]); this management was successful, and the expansion was completed to the planned-for volume. A double back-cut of the expanded flaps [37] was performed to maximize the gain from the expanded flaps; this allowed for full coverage of the resultant defects.

One point of criticism is that bearing a tissue expander on the head for 3-4 months will likely cause patients social- and work-related difficulties, so economic and social factors should be taken into account when indicating such a procedure. On the other hand, the non-treated patients suffer repeated attacks of headache and subsequently have repeated need for sick leave in addition to the psychological effects of the cosmetic disfigurement from the lesion. Therefore, bearing a tissue expander on the head for 3-4 months is made tolerable by the elimination of these symptoms.

\section{Conclusion:}

Careful planning for the management of large cirsoid aneurysm is crucial to assure uneventful 
outcomes. Three-stage management with application of tissue expanders and endovascular occlusion shortly before en bloc excision and reconstruction resulted in excellent results with no recurrence, no morbidity and an appealing cosmetic outcome.

\section{REFERENCES}

1- Khodadad G.: Familial cirsoid aneurysm of the scalp. J. Neurol. Neurosurg Psychiatry, 34: 664-667, 1971.

2- Khodadad G.: Arteriovenous fistula of the scalp. Ann. Surg., 177: 79 85, 1973.

3- Badejo L. and Rockwood P.: Case report: Traumatic arteriovenous fistula of the scalp. J. Neurosurg., 66: 773774, 1987.

4- Massimi L., De Bonis P., Esposito G., Novegno F., Pettorini B., Tamburrini G., et al.: Vertex scalp mass as presenting sign of a complex intracranial vascular malformation. J. Neurosurg. Pediatr., 3: 307-310, 2009.

5- Muthukumar N., Rajagopal V., Manoharan A. and Durairaj N.: Surgical management of cirsoid aneurysms. Acta. Neurochir. (Wien), 144: 349-356, 2002.

6- Shenoy S.N. and Raja A.: Scalp arteriovenous malformations. Neurol. India, 52: 478-481, 2004.

7- Fisher-Jeffes N.D., Domingo Z., Madden M. and de Villiers J.C.: Arteriovenous malformations of the scalp. Neurosurgery, 36: 656-660, 1995.

8- Li F., Zhu S., Liu Y., Chen Y., Chi L., Chen G., et al.: Traumatic arteriovenous fistula of the superficial temporal artery. J. Clin. Neurosci., 14: 595-600, 2007.

9- Gurkanlar D., Gonul M., Solmaz I. and Gonul E.: Cirsoid aneurysms of the scalp. Neurosurg. Rev., 29: 208-212, 2006.

10- Robbins S.L., Cotran R.S. and Kumar V.: Pathological basis of disease. $3^{\text {rd }}$ edn. WB Saunders Philadelphia P 505 .

11- Domingo Z., Fisher-Jeffes N.D. and de Villiers J.C.: Surgical management of arteriovenous malformations of the scalp. In: Shmidek H.N., editor. Operative Neurosurgical Techniques: Indications, Methods and Results. $4^{\text {th }}$ edn. Philadelphia: Saunders Company, p. 1331-1338, 2000.

12- Weinzweig N., Chin G., Polley J., Charbel F., Shownkeen H. and Debrun G.: Arteriovenous malformation of the forehead, anterior scalp and nasal dorsum. Plast Reconstr Surg., 105: 2433-2439, 2000.

13- Nagasaka S., Fukushima T., Goto K., Ohjimi H., Iwabuchi S. and Maehara F.: Treatment of scalp arteriovenous malformation. Neurosurgery, 38: 671-677, 1996.

14- Shepard R.H. Proceedings: Cirsoid arteriovenous malformations of the scalp. J. Neurol. Neurosurg. Psychiatry, 38: 827-828, 1975.

15- Schultz R.C. and Hermosillo C.X.: Congenital arteriovenous malformation of the face and scalp. Plast. Reconstr. Surg., 65: 496-501, 1980.

16- Berenstein A., Scott J., Choi I.S. and Persky M.: Percutaneous embolization of arteriovenous fistulas of the external carotid artery. AJNR Am. J. Neuroradiol., 7: 937-942, 1986.

17- Dandy W.E.: Arteriovenous aneurysms of the scalp and face. Arch Surg., 52: 1-32; 1946.

18- Barnwell S.L., Halbach V.V., Dowd C.F., Higashida R.T. and Hieshima G.B.: Endovascular treatment of scalp arteriovenous fistulas associated with a large varix. Radiology., 173: 533-539, 1989 .

19- Elkin D.C.: Cirsoid aneurysm of the scalp; report of four cases. Trans South Surg. Assoc., 57: 122-131, 1946.

20- Malan E. and Azzolini A.: Congenital arteriovenous malformations of the face and scalp. J. Cardiovasc. Surg., 8: 109-140, 1986.

21- Gupta A.K., Purkayastha S., Bodhey N.K., Kapilamoorthy T.R., Krishnamoorthy T., Kesavadas C., et al.: Endovascular treatment of scalp cirsoid aneurysms. Neurol. India, 56: $167-172,2008$.

22- Tiwary S.K., Khanna R. and Khanna A.K.: Craniofacial cirsoid aneurysm: 2-stage treatment. J. Oral. Maxillofac. Surg., 65: 523-525, 2007.

23- Kasdon D.L., Altemus L.R. and Stein B.M.: Embolization of the traumatic arteriovenous fistula of the scalp with radiopaque gelfoam pledgets. Case report and technical note. J. Neurosurg., 44: 753-756; 1976.

24- Hendrix L.E., Meyer G.A. and Erickson S.J.: Cirsoid aneurysm treatment by percutaneous injection of sodium tetradecyl sulfate. Surg. Neurol., 46: 557-560, 1996.

25- Heilman C.B., Kwan E.S., Klucznik R.P. and Cohen A.R.: Elimination of a cirsoid aneurysm of the scalp by direct percutaneous embolization with thrombogenic coils. Case report. J. Neurosurg., 73: 296-300, 1990.

26- Matsushige T., Kiya K., Satoh H., Mizoue T., Kagawa K. and Araki H.: Arteriovenous malformation of the scalp: Case report and review of the literature. Surg. Neurol., 62: $253-259,2004$

27- El-Shazly A.A. and Saoud K.M.: Results of surgical excision of cirsoid aneurysm of the scalp without preoperative interventions. Asian. J. Neurosurg., 7: 191-196, 2012 .

28- Senoglu M., Yasim A., Gokce M. and Senoglu N.: Nontraumatic scalp arteriovenous fistula in an adult: Technical report on an illustrative case. Surg. Neurol., 70: 194-197, 2008 .

29- Burrus T.M., Miller G.M., Flynn L.P., Fulgham J.R. and Lanzino G.: NeuroImages. Symptomatic left temporal arteriovenous traumatic fistula. Neurology, 73: 570, 2009.

30- Hochberg J., Ardenghy M. and Pait T.G.: Scalp tourniquet. Br. J. Plast. Surg., 47: 194-198, 1994.

31- Marotta T.R., Berenstein A. and Zide B.: The combined role of embolization and tissue expansion in management of arteriovenous malformation of the scalp. AJNR Am. J. Neuroradiol., 15: 1240-1246, 1994.

32- Hurwitz D.J. and Kerber C.W.: Hemodynamic considerations in the treatment of arteriovenous malformations of the face and scalp. Plast. Reconstr. Surg., 67: 421-434, 1981. 
33- Shultz R.C. and Hermosillo C.X.: Congenital arteriovenous malformation of the face and scalp. Plast. Reconstr. Surg., 65: 496-501, 1980 .

34- Horowitz J.H., Persing J.A., Nichter L.S., Morgan R.F. and Edgerton M.T.: Galeal-pericranial flaps in head and neck reconstruction: Anatomy and application. Am. J. Surg., 148: 489-497, 1984.
35- Fonseca J.L.: Use of pericranial flap in scalp wounds with exposed bone. Plast. Reconstr. Surg., 72: 786-790, 1983.

36- Elshahat A.: Exteriorization of buried port to salvage infected tissue expander. Eplasty, 9: e37, 2009.

37- Zide B.M. and Karp N.S.: Maximizing gain from rectangular tissue expanders. Plast. Reconstr. Surg., 90: 500504, 1992. 